\title{
Corpo e Cidade no Comércio Senegalês em Santa Maria (RS)
}

\author{
Filipe Seefeldt de Césaro ${ }^{1}$ \\ Maria Catarina Chitolina Zanini ${ }^{2}$ \\ ${ }^{1}$ Universidade Federal do Rio Grande do Sul, Porto Alegre, RS, Brasil \\ ${ }^{2}$ Universidade Federal de Santa Maria, Santa Maria, RS, Brasil
}

\section{Resumo}

Este artigo trata da venda de rua senegalesa em Santa Maria (RS, Brasil), procurando responder à seguinte pergunta: de que forma os vendedores de rua senegaleses estabelecidos em Santa Maria lidam com a constante perspectiva de perda de mercadorias frente às ações da fiscalização municipal? Partindo de uma pesquisa etnográfica desenvolvida entre agosto de 2016 e dezembro de 2017, procuramos perseguir dois objetivos principais: (i) descrever o aprendizado da investigação empírica na identificação e na interpretação social e histórica do fenômeno considerado; e (ii) descrever a relação corporal estabelecida por tais senegaleses com a materialidade urbana presente em seus espaços de trabalho irregular. Propomos que a forma prática pela qual os senegaleses concebiam tal materialidade urbana constituía o que chamamos de "saber estar", um conjunto de conhecimentos políticos de vigilância, antecipação, evasão e precaução dispendidos a fim de evitar a apreensão de mercadorias pelos fiscais públicos.

Palavras-chave: Migração Senegalesa. Venda de Rua. Corpo. Materialidade. Cidade.

\section{Body and City in the Senegalese Trade in Santa Maria (RS)}

\begin{abstract}
This paper deals with the Senegalese street sale in Santa Maria (RS, Brazil), trying to answer the question: How do the Senegalese street vendors in Santa Maria deal with the constant prospect of losing their merchandise in face of the actions of municipal inspection?. Based on an ethnographic research developed between August of 2016 and December of 2017, we sought to pursue two main objectives: (i) to describe the learning experience of empirical research in the identification and social-historical interpretation of the phenomenon under consideration; (ii) to describe the corporal relationship established by these Senegalese with the urban materiality present in their irregular spaces. We propose that the practical way in which the Senegalese conceived such urban materiality constituted what we call "knowingness", a set of political knowledges of surveillance, anticipation, avoidance, and precaution expended in order to avoid the seizure of merchandise by public inspectors.
\end{abstract}

Keywords: Senegalese Migration. Street Sale. Body. Materiality. City. 


\section{Introdução}

$\mathrm{O}$ presente artigo é fruto do aprofundamento de parte dos resultados analíticos alcançados em uma etnografia realizada entre 2016 e $2017^{1}$. No centro de atenção do trabalho anterior estavam as diferentes formas cotidianas de inserção no comércio informal de seis senegaleses estabelecidos na cidade de Santa Maria (Rio Grande do Sul, Brasil). Entre agosto de 2016 e dezembro de 2017, um dos presentes autores (Filipe de Césaro) desenvolveu trabalho de campo com tais imigrantes vendedores de rua, acompanhando seu ofício diário. Dividindo a tarefa de interpretar os caminhos empíricos resultantes, descrevemos, na pesquisa original, técnicas comerciais e sociabilidades relevantes para a inserção destes senegaleses no contexto social e histórico do comércio informal santamariense. Após o encerramento da mencionada pesquisa, De Césaro manteve contatos ocasionais com os interlocutores em seu cotidiano de trabalho, registrando informações que contribuem para o aprofundamento aqui pretendido.

Para isso, tomamos a concepção geertziana de etnografia (GEERTZ, 1989) como ponto de partida, concebendo o texto etnográfico como uma interpretação de interpretações em que o antropólogo constantemente relê, circulando do campo à escrita e vice-versa, as próprias induções parciais feitas sobre os fenômenos observados e as dinâmicas de sua cotidianidade (DAS, 2007). Disso resulta que, durante todo o trajeto de pesquisa, consideramos parciais nossas proposições analíticas, resultantes das negociações intersubjetivas que perduraram entre a observação participante, as conversas informais, a análise sócio-histórica e a escrita dialógica entre os autores² ${ }^{2}$ Além disso, os cuidados éticos com relação aos colaboradores da pesquisa também foram constantes.

\footnotetext{
Originalmente, tal etnografia resultou em uma pesquisa de Mestrado. Partindo da relação de orientação e de reflexões conjuntas entre os dois autores do presente trabalho, manteve-se o esforço analítico posterior de aprofundar os resultados alcançados na mencionada dissertação. De Césaro e Zanini desenvolveram a atual análise subsequente em conjunto, sendo que a investigação empírica ficou a cargo do primeiro. Vale destacar que alguns caminhos analíticos sinalizados no presente artigo foram melhor debatidos em tal dissertação, disponível em: https://repositorio.ufsm.br/ bitstream/handle/1/15916/DIS_PPGCS_2018_CESARO_FILIPE.pdf? sequence $=1$ sisAllowed $=\mathrm{y}$.

2 A inserção no campo em que De Césaro esteve presente se iniciou em 2015 e sem a intenção de pesquisa. À época, estabeleceram-se breves conversas informais com os senegaleses em seus pontos de venda, sendo que, em meados de 2016, o autor passou a participar de uma das atividades de extensão do MIGRAIDH (Grupo de Pesquisa, Ensino e Extensão Mobilidade Humana e Direitos Humanos, e Cátedra Sérvio Vieira de Mello UFSM), que envolviam aulas de português a um grupo de imigrantes de diferentes nacionalidades estabelecidos em Santa Maria. Desempenhando o papel de tutor provisório em tal ambiente de aulas, foi possível ao pesquisador estabelecer proximidade e relações de confiança com os dois senegaleses que, à época, participavam da atividade. Apresentando-lhes a proposta de pesquisa de Mestrado, começou a lhes acompanhar em seu dia a dia de trabalho nas calçadas, aproximando-se dos demais vendedores senegaleses e centrando uma investigação empírica nas interações face a face deste processo.
} 
O apontamento das complexas variáveis contextuais vinculadas à mobilidade internacional de senegaleses ao Brasil e à Argentina, como as relacionadas aos fatores de catalisação da migração, à religião murid e ao associativismo nos contextos de destino, já recebeu a atenção aprofundada de outros estudos (MAFFIA, 2010; BITTENCOURT; REDIN, 2015; DE CÉSARO; ZANINI, 2017; REITER, 2017; entre outros). Desse modo, apenas nos propomos a uma rápida contextualização inicial que nos leve ao caminho analítico pretendido.

De primeira vista, pode-se notar os anos de 1990 como marcantes no fluxo migratório de senegaleses à Argentina (ZUBRZYCKI, 2011), enquanto, no Brasil, a chegada de senegaleses se torna destacada entre 2007 e 2012 (BARBOSA; DE CÉSARO; ZANINI, 2017). Trata-se de dois dos novos destinos de uma mobilidade internacional historicamente consolidada no Senegal, agora voltada ao Sul Global por efeito do fechamento europeu de fronteiras e do melhor desempenho macroeconômico dos países do Cone Sul na década de 2000 (UEBEL, 2017). No país de origem, a emigração é concebida não só como uma oportunidade de melhoria da qualidade de vida dos migrantes e de suas famílias, mas também como empreendimento cultural e religioso de sacrifício. Nele, é comum que se remeta tanto ao imaginário do migrante que retorna triunfante à sua pequena cidade de origem quanto à trajetória de vida de Ahmadou Bamba. Líder fundador do mouridismo3, tal figura acumula episódios de migração como buscas sagradas de formação pessoal e conhecimento, algo que Fall (2017, p. 473, tradução nossa) identifica como uma "filosofia da mobilidade" construída sobre a noção de que a migração é uma "grande escola da vida".

Retraçando os caminhos de entrada tomados anteriormente pela onda imigratória haitiana, estes fluxos inéditos passaram a acessar o Brasil, na maioria das vezes, por meio da parcela peruana da Rodovia Interoceânica, partindo de Quito (Equador) (onde não lhes era demandado visto de entrada) (HERÉDIA, 2015). Foi esse o caso dos senegaleses chegados a Santa Maria entre 2014 e 2016, cidade de porte médio localizada no centro do Estado do Rio Grande do Sul (IBGE, 2010). No período, o grupo de seis imigrantes foi atraído pelas maiores possibilidades de emprego formal no Sul do Brasil conforme compartilhadas pelas redes sociais típicas para a migração internacional pós-colonial (SAYAD, 1998). Após situações de racismo e exploração do trabalho nas experiências de emprego local (MOCELLIN, 2017), a pequena comunidade formada se lançou à venda irregular nas calçadas da cidade ${ }^{4}$. Tal mudança de ofício significou, ao grupo, a imbricação cotidiana com um conjunto de relações de poder já estabelecidas entre atores sociais dedicados e/ou interessados ao comércio de rua (PINTO, 2015). Vendedores, comerciários do setor formal, poder público e imprensa estão entre os principais conjuntos de atores que, cambiantes em seus arranjos de disputa a cada circunstância, faziam variar a forma e o grau da atuação da Superintendência de Fiscalização ${ }^{5}$, órgão municipal

\footnotetext{
O mouridismo é uma corrente muçulmana sufi expressiva no Senegal. Todos os imigrantes senegaleses acompanhados na venda de rua em Santa Maria se identificavam como murids.

4 Durante o período da pesquisa, somente um dos seis senegaleses acompanhados recebera o status de refugiado. O pedido de refúgio ainda representa a possibilidade de regularização aos senegaleses recém-chegados, dada a série de vetos com que foi aprovada, em 2017, a nova Lei da Migração.

5 Parte da Coordenadoria de Fiscalização de Atividades Econômicas e da Secretaria de Município de Estruturação e Regulação Urbana de Santa Maria, a função da Superintendência de Fiscalização é especificada pelo Decreto Executivo n. 93/2017.
} 
direcionado ao confisco de produtos irregularmente comercializados nas calçadas santamarienses. Trata-se de um campo (BOURDIEU, 1990) de disputas históricas na cidade e que constantemente nos remete ao poder de determinadas relações e posições sociais.

Tendo isso em vista, inserir-se em tais espaços para vender exigia dos senegaleses, como já era realidade para os demais vendedores de Santa Maria, uma capacidade de interpretar o que se passava nos traços do entorno urbano imediatamente acessíveis durante o ofício para, momento a momento, agir sobre os mesmos como forma de diminuir as possibilidades de perda de mercadorias. Nessa esteira, é às técnicas corporais cotidianas desenvolvidas pelos senegaleses para lidar com sua situação de vulnerabilidade que pretendemos nos dedicar a seguir, aprofundando as reflexões iniciadas na pesquisa original já introduzida. Paralelamente, salienta-se que os migrantes senegaleses comumente já têm um aprendizado acerca da venda de rua ${ }^{6}$ e da migração no Senegal (STOLLER, 2002; RICCIO, 2005; GLOVER, 2007; ZUBRZYCKI, 2011; DE MELLO; TEDESCO, 2015): trata-se, portanto, de desenvolver novas e já estabelecidas habilidades em novo contexto interativo e numa historicidade em que esta prática está enquadrada na cidade de Santa Maria. Derivamos nossas proposições analíticas do diário de campo produzido por De Césaro que, no seio de tal empreendimento, desenvolveu observação participante e conversas informais com os seis senegaleses então atuantes no comércio de rua de Santa Maria. Chamamos os interlocutores de Abdoulaye (27 anos), Ahmadou (23 anos), Cheikh (25 anos), Maba (27 anos), Mamour (26) e Maodo (33), nomes fictícios que previnem a exposição desnecessária do grupo, que já é alvo pessoalizado das ações violentas dos agentes fiscalizadores em questão ${ }^{7}$. Pelo mesmo motivo, lugares também são denominados por nomes fictícios.

Para guiar a narrativa analítica dos dados empíricos, mobilizamos especialmente as categorias de corpo, materialidade, modo de fazer e agenciamento. Essas se mostraram relevantes partindo do fluxo originalmente tomado pelo trabalho de campo, formando uma linha teórica possível para a compreensão da imensa variedade de atos corporais dispendidos pelos senegaleses e que, conforme se percebeu em campo, justificavam-se pela necessidade de precaução e vigilância nas calçadas da venda. Questionamo-nos, então: de que forma os vendedores de rua senegaleses estabelecidos em Santa Maria lidavam com a constante perspectiva de perda de mercadorias frente às ações da fiscalização municipal? Começamos, agora, por descrever o caminho etnográfico que nos levou à análise do que passamos a chamar de saber estar. Esse recebe atenção específica subsequentemente.

\footnotetext{
Utilizamos a expressão venda de rua para designar o ofício de comercializar produtos em espaços públicos, englobando a exposição de produtos tanto de modo ambulante/itinerante quanto de modo fixo, sobre calçadas.

7 Recorrentemente, os senegaleses comentavam que os fiscais e guardas municipais eram pouco numerosos e que, por isso, sabiam identificar cada vendedor de rua senegalês entre as operações de apreensão de mercadorias. Os relatos sobre a perda de produtos em situações violentas foram comuns durante o trabalho de campo desenvolvido, ainda que nenhuma apreensão tenha sido testemunhada (provavelmente porque, com o tempo, os senegaleses passaram a expressar sua preferência de horários e dias, comumente os mais calmos, para que fossem acompanhados). Essa condição de investigação empírica encontrada, em que as circunstâncias violentas passadas e a preparação para as futuras eram assuntos diários nas calçadas da venda, levou-nos a centrar nossa análise na vivência cotidiana das apreensões de mercadorias como possibilidades sempre latentes, para as quais o corpo era preparado de determinadas formas. Com isto, também fizemos a opção ética de uma escrita que não identifique os sujeitos e os locais específicos de trabalho.
} 


\section{Aprendendo a Fazer Pesquisa em um Contexto Histórico de Ilegalidade}

Entre os esforços de pesquisa recentes acerca do fluxo de senegaleses ao Brasil e à Argentina, pode-se sublinhar uma direção marcante. Trata-se do enfoque analítico sobre as formas de associativismo postas em prática pelos diferentes grupos nos contextos urbanos locais em que se estabelecem, entre a manutenção de redes sociais e organizações políticas e/ou religiosas a servirem de porta-vozes para a comunicação coletiva dos senegaleses com o poder público, e a imprensa, os contratantes, a sociedade local e outros grupos imigrantes próximos (KLEIDERMACHER, 2013; ALVARADO; ZUBRZYCKI, 2015; HERÉDIA, 2015; GUILHERME, 2017; HEIL, 2018; entre outros). Mesmo tendo em vista a importância desta atenção difundida, expressa pela qualidade dos trabalhos relacionados, é possível notar que outras formas pelas quais os imigrantes senegaleses fazem política, menos institucionalizadas e evidentes, permanecem fora do escopo analítico desse conjunto de pesquisas. Queremos atentar para os agenciamentos, no sentido dado por Michel Callon (2013) ao termo, por meio dos quais os vendedores de rua senegaleses em Santa Maria se relacionavam com a materialidade urbana à sua volta para evitar as frequentes apreensões de mercadorias. Mas como isso foi identificado em campo?

A urbe do cotidiano laboral dos senegaleses em Santa Maria se constituía pela proximidade, por vezes até mesmo de poucos metros, em relação a um dos principais conjuntos de lojas do comércio formal da cidade. Majoritariamente situados em sentido diagonal à localização de tais lojas, na mesma quadra do espaço urbano, os senegaleses dividiam trechos de calçada com outros vendedores de rua: com a exceção dos casos minoritários em que o vendedor tinha bom relacionamento com algum lojista, os pontos de venda eram montados nos limites laterais dos acessos a prédios residenciais ou de empreendimentos de não concorrentes, como farmácias, restaurantes e museus. Nessa região de extensão próxima a duas quadras, ao longo de trechos de no máximo vinte metros, os vendedores de rua se aglomeravam de acordo com o costume de ocupação de cada grupo. Nas calçadas mais distantes desses espaços, outros vendedores também atuavam, mas ao longo de uma região próxima à extensão de seis quadras, ao longo das quais os pontos de venda se distribuíam de forma mais esparsa. De um lado a outro da avenida que acompanha todas essas quadras de distância, constituía-se um mapa de formato estreito em uma direção e comprido em outra, correspondente à maioria das atividades do comércio informal da cidade.

Com o tempo de trabalho de campo, essas características gerais da cidade acessada passaram por uma ressignificação. Conversas informais sobre os perigos de se vender irregularmente, dada a fiscalização ${ }^{8}$ constante dos arredores ocupados pelos senegaleses, foram o ponto inicial para que isso acontecesse. Em interações envolvidas nesse assunto, era comum que esses vendedores se mostrassem sujeitos políticos conscientes do espaço social em que se inseriam, expondo suas formas próprias de manter a cautela requerida pela profissão. Certa vez, Mamour se envolveu em uma discussão tensa com um professor universitário que, junto a estudantes, pretendia desenvolver uma aula prática de fotografia

Disponível em: http://www.camarasm.rs.gov.br/camara/proposicao/LeiComplementar/2012/1/0/9101. Acesso em: 10 jun. 2020. 
nas proximidades da venda de rua senegalesa. Moveu-se em direção ao homem, com ele argumentando e, em seguida, compartilhando seus motivos com De Césaro:

Um indivíduo, que me pareceu professor universitário, estava com um grupo de alunos fazendo fotos justamente no espaço ocupado pelos três senegaleses, e tudo permanecia calmo enquanto os fotógrafos, em ensaio, mantinham suas lentes em um cachorro que, curiosamente, dormia estirado no meio da calçada. Enquanto Maba e Ahmadou negociavam produtos com clientes, em dada hora, notei Mamour discutindo com esse homem [...]. Ao captar as frases "não, mas tu só tem que entender que é uma aula de fotografia... amanhã nós vamos voltar aqui" e "não pode tirar foto cara, tem que perguntar primeiro...", e notar a expressão dos alunos que já não fotografavam mais nada em volta, comecei a entender a situação. Após os clientes terem se retirado, Maba foi até lá intermediar, e eu permaneci imóvel [...]. Maba se aproximou muito mais calmo, em tom baixo: não pude ouvir nada, e parece que os ânimos não se acalmaram, com Maba voltando e Mamour ali ficando na discussão. Após algum tempo, o homem saiu e eu fiquei sem me mexer mais um pouco. Dentro de alguns minutos, fui até Mamour, que explicou tudo: tiravam fotos da paisagem, mas, em dado momento, um aluno posicionou a câmera de forma a captar o rosto do senegalês com clareza, algo que o incomodou. Não notei o estopim do desentendimento, mas me pareciam adequadas as razões do senegalês [...]. Isso tendo em vista que, como Maba e Mamour logo me relataram, não gostam de ser fotografados: pelo que disseram, já aconteceu de pessoas entregarem à fiscalização municipal fotos não apenas deles, mas dos produtos em exposição. Alguns deles já teriam ido tentar recuperar uma maleta na prefeitura e, lá, os fiscais teriam mostrado as "provas" entregues por algum acusador (De Césaro, diário de campo, 10/05/2017).

Ocasiões como essa gradualmente apontavam para a necessidade de, na interpretação dos dados empíricos, definir corpo não apenas como envolvido por técnicas do vender, articuladas nos gestos e na fala, por exemplo. Em outras palavras, o campo tornou necessário tratá-lo também como um lócus de técnicas do estar, articuladas na experiência e no aprendizado sensório de se fazer presente em um espaço habitado por atores cujas subjetividades eram permeadas, ali, pela violência de Estado (DAS, 2007). Em análise, procuramos, então, conceber o corpo como movimento de percepção (CSORDAS, 2008), lembrando que, de um papel social a outro, "[...] os atores decifram sensorialmente o mundo de maneira diferenciada" (LE BRETON, 2007, p. 55). É o corpo como ferramenta social e histórica de estar/ser no tempo e no espaço. Em outras palavras, como é necessário para observar técnicas de produção de espaços comerciais (DE CÉSARO; ZANINI, 2018), começou-se a notar em campo, outra vez, uma série de saberes corporais com os quais os senegaleses de Santa Maria vivenciavam seu cotidiano enquanto vendedores de rua. Entretanto, agora, tais conhecimentos se mostravam voltados a evitar que a aproximação de fiscais passasse despercebida a estes vendedores: ao invés de saberes sobre como interagir nas situações face a face, eram saberes sobre como sentir os espaços urbanos ocupados.

Os fotógrafos em treinamento, flanando pelo centro de Santa Maria com suas câmeras a registrar tudo e todos, percebiam e significavam aquela redondeza de uma forma diferente (e oposta) àquela realizada pelos vendedores senegaleses. Como explicita a reação de Mamour, esses imigrantes reconheciam uma possível agência indesejada de materialidades circundantes caso fossem captadas em fotos (MEYER, 2010) uma virada de perspectiva, aliás, em relação a como essas pareciam entendidas pela turma acadêmica como resultado da câmera como um olho de Deus (HARAWAY, 1988). Desse modo, trata-se de um grupo de indivíduos inseridos na condição de aprendizado do migrante internacional (SAYAD, 1998). Sobre isso, frequentemente, comentavam não 
só sobre as diferenças da relação cliente-vendedor em comparação às que vivenciavam no Senegal, mas também sobre as diferenças de legalidade da atividade informal em ambos os países: em sua experiência no país de origem, comumente, essa também era irregular, mas, de tão costumeira, acabava relevada pelas autoridades municipais. Entre o aqui e o lá, em um cotidiano de contatos transnacionais facilitados (FOURON; GLICKSCHILLER, 1997; GLICK-SCHILLER; LEVITT, 2004; VERTOVEC, 2009), os imigrantes senegaleses acompanhados tinham de reinventar a si mesmos na experiência do comércio de rua, aprendendo um sentido político da vida urbana que, até então, era desconhecido.

E os efeitos desta realidade no trabalho de campo realizado foram claros ao autor presente nas calçadas da venda de rua senegalesa em Santa Maria. Na maioria das vezes em que acompanhava os senegaleses em seu ofício, De Césaro percebeu que os mesmos não perdiam a oportunidade de lhe dar dicas acerca da percepção sensória do mundo. O autor, mesmo após meses de presença em campo, por vezes se posicionava e se movimentava sem as precauções necessárias (DE CÉSARO, 2018), levando em conta apenas as necessidades de sua observação participante e, no máximo, a preocupação em não atrapalhar as interações entre senegaleses, clientes e outros vendedores de rua. Essa era a percepção perdurante do antropólogo em relação aos espaços compreendidos pelos pontos de venda dos vendedores de rua senegaleses. Na condição de aprendiz permanente dos exercícios de atenção dos interlocutores, era frequente que De Césaro cometesse deslizes ao conceber como passivo o background daquelas interações humanas. Já os senegaleses, a corrigirem as práticas corporais do antropólogo, pensavam-na como constituída por elementos materiais agentes: a qualquer momento, por exemplo, uma esquina poderia deixar de significar acesso a transeuntes para se tornar um ponto estratégico de aproximação de fiscais da prefeitura.

Daí a necessidade de pensar questões como a distância dos pontos de venda em relação a tal esquina, o posicionamento ideal para melhor observá-la, e suas características físicas (se seu formato possibilita ou dificulta a visibilidade dos pontos de venda próximos). Nas incessantes correções feitas pelos interlocutores, o antropólogo estava a ser treinado para estar naquele espaço. Assim, até o fim de seu trabalho de investigação, De Césaro continuou a aprender a como significar politicamente os espaços urbanos de sua pesquisa empírica, de modo a não prejudicar uma vigilância que os senegaleses mantinham a todo o momento. Com o tempo, aprendeu-se que tal tarefa correspondia a um constante desconfiar do ambiente que, no papel do antropólogo em campo, também era desconfiar de si mesmo.

Em segundo momento do trabalho etnográfico, no qual cada retorno aos registros de campo incessantemente lhes joga nova luz (PEIRANO, 2014), esse posicionamento de si em campo foi atualizado pela evidência de clivagens de raça e nacionalidade características da história do Brasil-nação (SEYFERTH, 1996). Uma das situações sintéticas nesse sentido envolveu um cliente branco insatisfeito com o defeito apresentado por um relógio comprado de um vendedor senegalês que, insistia ele, era Mamour. Esse alegava que aquele acessório não fazia parte dos modelos por ele vendidos, enquanto o homem esbravejava que os senegaleses "são tudo igual" e que, por isso, não teria como distinguir um vendedor de outro para demandar a troca de mercadoria. Frente à contra argumentação de um vendedor brasileiro próximo, o cliente rebateu: "não, eu já falei com 
todos esses moreno... foi de um moreno que eu comprei aqui, tenho certeza... mas aí fica nessa de passar pro outro a responsabilidade..." (De Césaro, diário de campo, 22/03/2017). O autor branco relendo passagens como essa foi gradualmente levado a identificar sua pele em campo como a prerrogativa primária para a atitude antes predominante de naturalizar a presença e a objetividade de si nas calçadas da venda senegalesa. Desse modo, mais do que uma condição para a "coleta de dados", aprender com os interlocutores uma corporificação específica ao contexto significou, aqui, questionar a invisibilidade positivista branca (HOOKS, 1992) que era compartilhada com aquele cliente indignado, cada um (des)marcando a própria presença racial - e marcando a do Outro - de acordo com suas identidades sociais em jogo nas calçadas.

As próximas seções são atravessadas por esta reflexão a partir de três considerações próximas do cotidiano senegalês acompanhado: (i) a pele negra referenciada por brancos pelos vocativos "moreno" ou "negão" expressa parte do decoro racista tipicamente brasileiro (SCHWARCZ, 2012); (ii) a representação social hegemônica do estrangeiro o define como uma essência e, assim, algo inabilitado ao reconhecimento (HONNETH, 2011); e (iii) o pertencimento de classe média, branco e brasileiro de pesquisadores é uma variável em constante negociação com as interpretações etnográficas propostas (HARAWAY, 1988).

Essa reflexividade ensejada in loco é que nos direcionou a rever as situações em que o sentido dado por De Césaro à cidade era considerado inadequado pelos senegaleses. De modo a aguçar sua percepção do entorno para nele se portar em contribuição à própria investigação empírica, o autor em campo passou a atentar, por exemplo, para os procedimentos cautelosos que tais vendedores cumpriam no processo de composição cotidiana de cada um de seus pontos comerciais. Com grande frequência, isso envolvia perceber quais pontos da cidade eram mais importantes aos interlocutores em cada situação de campo, posicionando-se de modo a não atrapalhar sua observação, bem como quais momentos do expediente eram adequados ou não para perguntas, comentários ou mesmo alguma ajuda direta do pesquisador (na montagem dos pontos de venda em dias muito ventosos, por exemplo). Ademais, entre o campo e a escrita, um olhar aguçado para o conteúdo racial e xenófobo sempre potencial nas interações cotidianas desses vendedores.

\section{A Política Pública para o Comércio de Rua em Santa Maria (RS)}

De outro lado, procedimentos análogos a estes podiam ser notados entre os demais vendedores de rua irregulares. Esses também se mostravam similarmente preocupados, de suas formas autênticas, em se precaver contra a latente possibilidade de aproximação de agentes fiscalizadores. Por toda a parte visível das calçadas ocupadas durante o trabalho de campo, figuravam olhos bem abertos em um circuito marcante que, de um lado a outro, repetia-se a dar certa sincronia rítmica e sensória a uma relação de poder comum aos que ali se posicionavam para vender. Entre passos a contornar produtos para o atendimento a interessados, braços ofereciam e recolhiam produtos, mas sem ficarem afastados por muito tempo do apoio traseiro mais próximo, como modo de ampliar o 
campo de visão dos dois sentidos da calçada. As pernas seguiam, majoritariamente, a mesma lógica: era comum o agachar para, de uma posição inferior, mirar clientes nos olhos enquanto lhes era alcançado algum produto. Ainda assim, isso era feito sempre dentro de períodos de tempo que pareciam previamente estimados pelos vendedores, de modo que os pés nunca eram cruzados relaxadamente: ao invés disso, mantinham-se prontificados para o rápido caminhar de um escape.

Ademais, aquele cotidiano laboral continha pistas a algumas das diferenças técnicas de cada grupo de vendedores, por vezes evidenciadas em situações de estranhamento, como quando Mamour disse dar dicas a um vendedor de morangos que, a seus olhos, montava pontos de venda vulneráveis e, em partes por isso, tentava escapar das apreensões demasiadamente cedo, deixando para trás a maior parte do estoque exposto. Tendo em vista que a história dá movimento à dimensão prática da cultura por meio das relações de poder conjunturais nas quais indivíduos e grupos se inserem (SAHLINS, 2003; PISSOLATO, 2015), tivemos de remeter ao contexto social e histórico que tornava significativo esses aprendizados vividos e observados em campo. Em outras palavras, o sentido cultural dessas práticas corporais identificadas, ao ressignificarem a porção de Santa Maria diariamente ocupada pelos vendedores senegaleses, emerge por estar envolvido em determinada historicidade do comércio de rua local em suas relações de classe e raça.

A proibição do comércio de rua em Santa Maria foi realizada pelo mesmo processo jurídico que criou o Shopping Independência em 2010, espaço fechado destinado a regularizar os vendedores atuantes nas calçadas da cidade (DOS SANTOS, 2011). Em 2012, a Lei Complementar n. $92^{9}$ atualizou as normas de fiscalização do comércio de rua, apenas legalizado para a venda de artesanatos, tradicionalmente realizada por grupos indígenas e demais artesãos. Aos vendedores não regularizados no espaço do Shopping Independência, que costumavam relatar a falta de vagas para ingresso no mesmo ou a desvantagem econômica de fazê-lo, restava um cotidiano laboral de risco. Ao longo desse, circulavam latentes perspectivas de algum fiscal que se aproximaria, de certo lojista que havia feito uma denúncia às autoridades, de tais clientes que haviam defendido a honestidade dos vendedores informais, da atuação do MIGRAIDH ${ }^{10} \mathrm{em}$ defesa dos vendedores senegaleses e de algum veículo midiático que havia feito uma matéria de ataque ou defesa do comércio de rua irregular. Essa conjuntura instável e marcada pelo conflito constituía de uma tendência consolidada desde os anos 1980, quando a regularização do (já difundido) comércio de rua em Santa Maria começou a ser concretizada pelo poder público (PINTO, 2015). Referimo-nos aqui ao duradouro embate entre duas noções contrárias de espaço público, processo histórico também presente em outras cidades brasileiras de expressivo comércio informal (MARQUES; CAVEDON; SOILO, 2013).

De um lado, diferentes grupos de comerciantes respondem às conjunturas de desemprego se lançando às calçadas, concebendo-as como lugares temporários de

\footnotetext{
Disponível em: http://www.camarasm.rs.gov.br/camara/proposicao/leicomplementar/2012/1/0/9101. Acesso em: 10 jun. 2020

10 Grupo de Pesquisa, Ensino e Extensão Mobilidade Humana e Direitos Humanos, e Cátedra Sérgio Vieira de Mello UFSM. O MIGRAIDH está entre os coletivos de maior destaque no apoio jurídico-político aos imigrantes de diferentes origens estabelecidos em Santa Maria.
} 
sobrevivência que, com a necessidade de permanência maior, passam a ser lugares fixos de profissão. Grupos de clientes envolvidos não apenas nas interações de compra e venda, como também nas sociabilidades que delas emergem, tendem a se posicionar em favor a tal comércio informal. O mesmo costuma ser feito pelo estrato alternativo da imprensa local que tem dentre seus objetivos o de reimaginar, de forma inclusiva, a cidade na qual se vive. Em posição oposta, costumam estar a administração pública, os comerciantes formais e a imprensa local mainstream, propondo resoluções técnicas e instantâneas ao problema da venda de rua. Nesse caso, é comum que se ligue o comércio irregular ao contrabando, à pirataria, à poluição da paisagem e ao agravamento das condições de segurança pública.

No caso dos senegaleses, tais elementos negativos ligados ao ofício são comumente epidermizados (FANON, 2008) e colados ao imigrante enquanto bode expiatório (SAYAD, 1998), de maneira análoga a tantas outras destinações urbanas desse fluxo humano (JARDIM, 2013; PACECCA; CANELO; BELCIC, 2017; KLEIDERMACHER, 2019; NDIAYE, 2019). Mesmo sob uma linguagem que procura se refugiar no campo discursivo das relações de produção e consumo amparadas por lei, a narrativa hegemônica destes grupos de interesse opera pela lógica do que Homi Bhabha (1998) chama de discurso colonial. Ora conhecida pelo fetiche, como quando se fala em imigrantes aliciados por uma rede criminosa, ora desconhecida pela repulsa, como quando se fala em imigrantes com intenções criminosas na venda de rua, a diferença é tomada como objeto de vigilância, e não de compreensão. Tem-se aí uma expressão local, na cidade comumente chamada de "Coração do Rio Grande", de uma noção de identidade gaúcha constituída na distinção entre populações de ascendência europeia daquelas de origem afro-indígena em termos de disposição ao trabalho produtivo (OLIVEN, 1992).

A criação dos denominados shoppings populares (em Santa Maria, o Shopping Independência) como pretensas formas de extinguir o comércio de rua representam, assim, a dimensão prática desta posição dominante. "O ideal seria uma cidade sem ambulantes", opinava o Diretor Geral de Indústria, Comércio e Turismo de Santa Maria em 1991, mesmo ano de implementação do Camelódromo Municipal, outro espaço de regularização aos moldes dos mencionados shoppings populares (PINTO, 2015, p. 38). Em setembro de 2017, o Diário de Santa Maria $^{11}$, um dos principais veículos midiáticos da cidade, publicou matéria online sobre o comércio de rua de então. Na reportagem, reitera-se a ilegalidade dos vendedores de rua em um tom de denúncia pública: ou melhor, performa-se a noção de ilegal (SANTOS, 1982; RABOSSI, 2011; SOILO, 2017; entre outros) de um ponto de vista normativo e linear, confrontada pelo sentido paralelo que a ela é dado pelos senegaleses e outros vendedores desta cidade (DE CÉSARO, 2018). E, ainda que alguns dos mesmos tenham sido entrevistados de acordo com suas razões, a matéria ressalta promessa feita pelo então prefeito Jorge Pozzobom ao periódico: "Vamos tratar essas questões com regramento. Não é crível, não é aceitável que algumas pessoas paguem suas taxas e alvarás, e outras vão para rua sem vigilância, sem fiscalização. O Centro é de todos, não podemos permitir essa esculhambação. Vamos enfrentar tudo. Até o final do ano, estaremos com tudo delimitado, e a bagunça que está no Centro, não terá mais". Tanto naquele quanto nesse contexto, em suma, a regularização foi tratada como sinônimo de anulação do comércio

${ }^{11}$ Disponível em: https://diariodesantamaria.atavist.com/onde-quase-tudo-pode. Acesso em: 10 jun. 2020. 
de rua, num modelo de cidade a pretender calçadas livres, vitrines desobstruídas, atitude pública blasé e lojas cheias (DELGADO; MALET, 2007).

Vale salientar o distanciamento de tal modelo de urbanidade, expresso na mencionada estratégia de regularização, em relação à realidade cotidiana dos vendedores de rua com os quais se teve contato em trabalho de campo. O remanejo de vendedores de rua a um espaço como o Shopping Independência encontrava limitações não só no número insuficiente de vagas ( sublinhado pelo persistente crescimento de irregulares nas calçadas quando das conjunturas de crise econômica), mas também (e principalmente) na falta de diálogo do poder público com os grupos de trabalhadores impactados. O resultado é uma política que desconsidera as dificuldades da transição de um ambiente de comércio informal a outro formal, dados os saberes e significados interacionais distintos que cada um desses espaços sociais demanda (MARQUES; CAVEDON; SOILO, 2013). Em suma, seja pelo número limitado de vagas ou pela desistência em razão dos baixos lucros do período de reaprendizado comercial, trata-se de uma postura de administração pública fadada a manter ilegal parte dos vendedores de rua da cidade. Com o espaço regular lotado e as calçadas crescentemente preenchidas por novos vendedores de rua não contemplados ou não adaptados ao mencionado shopping, a conjuntura do trabalho de campo realizado evidenciou esta tendência: reprimir os que estão na rua, alegando sua irregularidade mesmo que não houvesse caminhos viáveis para a regularização.

Essa insistente via da repressão, que parece mais mostrar serviço a quem acusa os vendedores de rua de competição desleal do que alcançar a solução prevista pela própria lei, repetia a atuação do poder público historicamente consolidada em Santa Maria. Baseava-se em mais uma transferência de trabalhadores assentada na expectativa de que as atividades informais nas ruas viriam a se esgotar, como se o comércio de rua não constituísse de uma realidade social densa e historicamente consolidada em Santa Maria. Entre o fim de 2018 e o início de 2019, o mesmo cenário se repetiu. Com a pressão de lojistas e imprensa, agora formalizada pelo novo Comitê de Combate ao Comércio Informal de Santa Maria, bem como por um ponto de fiscalização fixa nas regiões ocupadas pela venda, os senegaleses contatados em campo pararam de trabalhar, alguns tendo de se mudar temporariamente para atuar em outras cidades ${ }^{12}$. Passado o período natalino de consumo ampliado, novamente vieram à tona a inviabilidade da repressão constante e, assim, o caráter privado das forças que se esforçam por levar tal política pública às suas últimas consequências. Os vendedores gradualmente voltaram às ruas e ao perigoso jogo de trabalhar sob a mira das apreensões ocasionais.

Ao descrever os procedimentos autênticos e contínuos por meio dos quais se resiste a relações de poder cotidianas, esperamos revelar certos detalhes habituais de uma maneira específica de trabalhar que forneçam aos níveis formais de negociação (entre associações de senegaleses, prefeituras, organizações de apoio, etc.) novos elementos de debate em torno de planejamentos alternativos de regularização laboral. Advogamos pela consideração, nas instâncias de alta política, dos fazeres constituídos em nível da política

\footnotetext{
${ }_{12}$ Duas matérias on-line destacam-se na superficial legitimação destas circunstâncias repressivas no que toca à venda de rua irregular na cidade. Disponíveis em: https://diariosm.com.br/not\%C3\%ADcias/economia/estudo-sobre-com\%C3\%A9rcioinformal-de-santa-maria-\%C3\%A9-apresentado-no-f\%C3\%B3rum-das-entidades-1.208454l e http://www.santamaria. rs.gov.br/noticias/17692-posto-de-fiscalizacao-da-prefeitura-ira-combater-o-comercio-informal-no-centro-da-cidade. Acesso em: 10 jun. 2020.
} 
das calçadas pelos mais impactados por uma legislação (FONSECA; SCALCO; DE CASTRO, 2018). Em sua potencialidade subversiva, tais capacidades sinalizam a necessidade de soluções alternativas às vigentes em contextos como o de Santa Maria.

\section{Construção e Prática de um Saber Estar na Venda de Rua}

Inseridos cotidianamente nesta estrutura histórica, aos senegaleses era fundamental compreender em quais pontos deveriam focar com maior intensidade a cada período do dia de trabalho, dadas as informações e rumores trocados entre vendedores, o fluxo de clientes e o histórico recente de apreensões. E, paralelamente, o rodízio regular de linhas, contornos e enfoques dispendidos corporalmente pelos vendedores contava sempre com o improvável. Ali é de onde normalmente eles vêm, mas nada impede que, dessa vez, venham de lá e não sei, ainda não vi fiscal, mas não sei eram tipos de frases bastante ouvidas. Em certa ocasião, em que De Césaro comentava a um dos senegaleses que o local de venda no qual se encontravam lhe parecia de fácil vigilância pelo vendedor, deu-se a seguinte resposta: "mas aqui o fiscal pode chegar dali, ó... [apontando com o dedo da mão esquerda] Se vem dali, eu nem vejo..." (de Césaro, diário de campo, 4/10/2017).

Nesse sentido, a densidade do fluxo de transeuntes, a largura de ruas, calçadas e travessas, os bloqueios provisórios de tapumes a proteger obras ou reformas, a necessidade (causada pela chuva) de trabalhar sob a cobertura de marquises e a proteção lateral fornecida por largas colunas de prédios antigos, por exemplo, apresentavam-se não como realidades materiais e objetos dados a formarem um mero fundo da verdadeira vida social. Eram o que Amade M'Charek (2010) conceitua como uma materialidade da diferença, um conjunto de objetos tratados como, paralelamente, o resultado e a continuidade indeterminada de uma rede de práticas sociais variadas e as diferenças por elas geradas relacionalmente nos cruzamentos entre trajetórias humanas e não-humanas.

Assim, tanto o fotógrafo quanto o pesquisador ali presentes, nas situações de campo narradas há pouco, tiveram suas práticas corporais sobre os pontos de venda enredadas aos demais conteúdos simbólicos vinculados à materialidade desses espaços pelos senegaleses. Perigo, passagem, permanência, fuga, proteção e atenção estão dentre apenas alguns desses conteúdos, não autossuficientes em sua significação do mundo material, mas imbricados (e reagentes, como vimos) ao sentido carregado pelas práticas corporais próximas sobre a mesma materialidade. Isso nos leva a pressupor que os elementos que compunham tal materialidade possuíam agência, pois se demonstravam como eixos a atarem diferentes interferências humanas cujos efeitos sociais não necessariamente se alinham às intenções simbólicas originais produzidas por cada indivíduo envolvido (LATOUR, 1993). Mantendo isso em mente, passamos agora a aprofundar, com algumas dinâmicas de maior destaque empírico, como os vendedores de rua senegaleses em Santa Maria construíam e praticavam uma significação própria acerca da materialidade urbana que cercava seus pontos de venda.

O trabalho de campo inteirado das mencionadas diferenças, especialmente as que impactavam o antropólogo engajado em observação participante e conversas formais, gradualmente levou nossa atenção para o convívio entre, por um lado, as formas 
particulares com que cada grupo interpretava os arredores materiais do comércio de rua santa-mariense e, por outro, certos consensos acerca da territorialidade adequada para que a atenção corporal de cada grupo pudesse ser desenvolvida. Em outros termos, pontos de passagem de transeuntes, esquinas estratégicas para a observação do horizonte próximo, ou ainda pontos de venda já costumeiramente mantidos por certo grupo de vendedores não poderiam ser desavisadamente ocupados sem prejuízos à vigilância desempenhada pelos vendedores. Quando isso ocorria, era frequentemente na forma de impedimento das práticas corporais que, ao partirem de cada grupo de vendedores, entrecruzavam-se ao intervirem na materialidade urbana do entorno. Nesse sentido, em várias ocasiões, vendedores de rua discordavam acerca de quais pontos de acesso às mercadorias eram os mais vantajosos à ação dos agentes fiscalizadores. Ainda assim, mantinham sua discussão dentro de certo número limitado de materiais urbanos concernentes a esse tema e, portanto, relevantes para dada região do comércio de rua santa-mariense. Partindo deste consenso mínimo, pressupunham quais espaços recebiam o interesse da observação vigilante que era cotidianamente realizada. Ao invés de regras demarcadas acerca da significação de cada elemento da cidade imediata, então, o objeto de concordância nesse contexto social era a desobstrução das práticas corporais alheias: certa travessa poderia significar perigo a uns e tranquilidade a outros, mas deveria poder ser observada enquanto tal por cada um dos envolvidos.

Uma circunstância específica do trabalho de campo remete a esta realidade. Trata-se de conversa informal tida com um vendedor de rua (chamado aqui de Mateus) bastante próximo dos senegaleses, e com o qual De Césaro costumava manter contato regular. Perto de seus DVDs de filmes e jogos eletrônicos, mantidos em um suporte metálico que o vendedor carregava com facilidade, notavam juntos alguns vendedores que ocupavam as calçadas mais próximas, e os quais nunca haviam visto pelos arredores do comércio de rua santa-mariense. Esses recém-chegados pareciam se dedicar, sobretudo, à venda de perfumes, pequenas máquinas de costura e variados acessórios em couro. A exposição de tais produtos, naquela ocasião, ocorria em espaços que De Césaro já havia notado serem reservados, pelos demais vendedores de rua, a se manterem vazios. Ali, o mais comum era que fossem abertos intervalos entre um ponto de venda e outro, de modo que os movimentos de um não atrapalhassem os de outro e, especialmente, que certa margem de visão lateral fosse igualmente reservada a todos os vendedores envolvidos. Nos comentários partilhados, Mateus não perdeu a oportunidade de avaliar a posição desses vendedores recém-chegados, criticando o fato de que, com indiferença, tomavam conta de um fragmento material da cidade que deveria estar desobstruído para as práticas corporais interpretativas dos demais trabalhadores locais:

o primeiro assunto em que tocamos foi o de sua localização atípica, ao menos a meus olhos: "e hoje tu tá por aqui, cara?", perguntei, solicitando simpaticamente por explicação. "Pois é, tem uns baianos ali onde eu fico, uns caras folgados... cheguei ali, tava o Ahmadou na minha direita não muito longe... aí o cara chegou e se enfiou no meio de nós dois, ai eu vim pra cá... pra não me incomodar, pra não dar tumulto, eu vim pra cá!", respondeu. Ao contrário do curto relato dos senegaleses sobre a presença inédita em seu espaço de venda, Mateus demonstrava irritação em suas palavras, destacando que o lugar não é dele, mas que achava necessária uma dose de bom senso na divisão do espaço entre vendedores de rua. Após sua reclamação, comentei: "ah, eu vi ali, mas achei que fosse aquele vendedor lá da Catedral, que vende com um 
carrinho de mercado... passei ali e achei que fosse ele...". "Não, não, aquele tá lá na Catedral ainda... esses aí não são daqui, são da Bahia, ou sei lá... falam diferente, nunca tinha visto eles aí, daí chegam fazendo isso... e tem lugar, cara, tem ali por exemplo [apontando para o outro lado da Rua B, em um ponto de venda desocupado localizado à frente do Banrisul]", retrucou Mateus, com face agressiva. Concordei com ele em seu argumento, que consistia em se eximir da pretensão de ser dono daquele espaço, mas, ao mesmo tempo, em defender sua primazia em ocupá-lo a partir do fato legitimador de que o faz diariamente: "não, a gente só trabalha ali, não somos donos da calçada... mas a gente mora aqui em Santa Maria né, eu, o Ahmadou, os guris ali... a gente vende todo o dia ali... aí chegaram os caras e agora tá cheio de gente ali, é até perigoso por causa da fiscalização", comentou em certa altura. Em suma, o vendedor argumentava por sua prioridade na ocupação daquele espaço mais movimentado, algo relativamente consensual entre os ocupantes comuns do centro da cidade para práticas de venda: sabe-se onde se pode ocupar "por direito", e quando se pode fazê-lo "por oportunidade" quando o vendedor legítimo, por algum motivo, não se encontra ali. É assim que os artesãos hippie, os vendedores de morangos, os senegaleses, os vendedores de panos de cozinha, os vendedores de amendoim doce e os vendedores de DVDs (como Mateus), dentre tantos outros, constroem cotidianamente um espaço comercial regular, ordenado quanto aos pontos de venda (onde estão, o quão grandes são e como se cruzam) e suas lógicas temporais de ocupação (quando se pode apropriar de um ponto do qual não se pertence). Com a chegada de indivíduos não inseridos nesse ambiente interacional, $e$ pouco familiarizados com as práticas de venda e sentidos espaciais que ali são vividos, logo são potencializados conflitos e tensões, como se observa na indignação relativa de Mateus (De Césaro, diário de campo, 04/10/2017).

Mais uma vez, a materialidade urbana se revelava um ponto de articulação de diferenças geradas por práticas corporais conflitantes. Torna-se possível notar, então, a importância do trabalho de significação da cidade levado a cabo pelos corpos dos diferentes vendedores de rua com os quais se teve contato. É nessa esteira que passamos a refletir analiticamente em termos de um saber estar. O definimos como um repertório de conhecimentos práticos, expressos em técnicas corporais (MAUSS, 2014), concernentes à necessidade de antecipação das operações de fiscalização municipal do comércio de rua santa-mariense. Mesmo que constituída em processos de diferenciação interétnica em relação a clientes e outros vendedores, conforme aprofundamos em outro trabalho (DE CÉSARO; ZANINI, 2018), queremos salientar aqui o fato de este repertório se definir por um tipo de relação humano-material.

Especificamente aos senegaleses, isso significava saber não apenas por quais pontos de acesso os agentes fiscalizadores teriam maior chance de se aproximar das mercadorias irregulares sem que o vendedor pudesse escapar com as mesmas, ou mesmo por quais desses pontos tais agentes mais circulavam, mas também qual a melhor forma de vigiar cada ponto de venda tendo vista suas especificidades materiais e a seletividade racial das operações de apreensão. É por isso que, em trabalho de campo, pôde-se observar a tendência, entre os vendedores de rua senegaleses, de alternância regular entre os mesmos pontos de calçada costumeiramente ocupados. A frequência não só lhes tornava usuários mais legítimos desse número limitado de pontos aos olhos dos demais vendedores próximos, como também, especialmente, era condição fundamental para que construíssem caso a caso o mencionado saber estar. Era preciso estar e sentir a materialidade de um ponto de venda para aprendê-la e, assim, compreender circunstancialmente as suas linhas de perigo e vantagem. Foi o que ficou claro quando, em certa ocasião, Cheikh explicou a De Césaro as suas razões para passar a evitar dado ponto de venda que antes 
era utilizado com frequência: ali, ficava-se próximo demais de um trecho de rua, do qual, portanto, fiscais desembarcados de um veículo poderiam facilmente apreender os produtos expostos. E mesmo no ponto de venda mais seguro escolhido desde então, o vendedor senegalês mantinha vigilância constante sobre os fluxos humanos bidirecionais nas calçadas e sobre um terceiro acesso que, perigosamente, aproximava-se da retaguarda do ponto de venda montado.

Daí surgia a possibilidade de se evitar situações de embate como a narrada há pouco, protagonizada por Mateus e seus amigos senegaleses. Enquanto ocupantes costumeiros de determinados pontos de venda do centro da cidade, esses imigrantes se tornavam encarregados de sua vigilância. E, na medida em que era embasada em saberes específicos sobre a materialidade que constituía tais locais, esta atividade se mostrava condição para a segurança dos outros grupos de vendedores atuantes em pontos próximos. Aos procedimentos corporais paralelamente resultantes e produtores deste saber estar senegalês, damos o sentido de modos de fazer, conforme define Michel De Certeau (1984). Para o autor, os modos de fazer são as práticas cotidianas de resistência geradas " [...] pela criatividade dispersa [...] e cambiante de grupos ou indivíduos já tomados pelas redes da 'disciplina'" (DE CERTEAU, 1984, p. 14-15, tradução nossa). Viver em uma situação de ilegalidade nas calçadas, além de condição submetida à disciplina jurídica municipal, significava também estar à procura de formas instrumentais, cotidianas e discretas de seguir em frente com o que era tratado como um "trabalho vil" (HOLANDA, 2004) característico destes imigrantes negros. Dessa realidade resultava a interpenetração diacrônica entre os vendedores de rua senegaleses e as variações da paisagem urbana entre cada um dos diferentes pontos de venda ocupados (DE CERTEAU, 1984; ECKERT; ROCHA, 2003; MASSEY, 2008; VEDANA, 2017). Nesses espaços, o saber estar emergia de forma adaptável, entre o conhecido e o perceptível, bem como entre cooperações e conflitos das quais se fazia aquele espaço mercantil (POLICASTRO; RIVERO, 2005).

A questão dos produtos selecionados para venda em cada ocasião nos remete a tal característica desse saber estar. Frequentemente, os vendedores senegaleses contatados explicavam, em campo, as razões pelas quais haviam escolhido vender este produto, $e$ não aquele. Como deviam fazer essa escolha antes da saída de suas casas, comentavam que se decidiam com base no que esperavam encontrar nos pontos de venda a serem ocupados: uma temporalidade estranha ao pesquisador em sua posição de classe, raça e nacionalidade, já que baseada na incerteza e na angústia como marcas da violência estrutural (FARMER, 2004) em jogo neste caso. De um lado, estavam as opções de exposição comercial com diferentes características de segurança ao vendedor, sendo as maletas mais portáteis e capazes de carregar menos produtos, e as lonas mais portáteis e capazes de carregar maior quantia. De outro, considerava-se o ponto de venda e suas possibilidades latentes de variação. Desse modo, alinhar a materialidade prevista para cada ponto de venda com a materialidade conhecida da maleta de bijuterias ou das extensas lonas de roupas (DE CÉSARO; ZANINI, 2017) se revelava uma experiência cotidiana relevante entre os vendedores de rua senegaleses em Santa Maria. Propomos que tal capacidade específica, assim como as demais descritas como componentes de um saber estar senegalês na venda de rua, define-se como um agenciamento mercadológico, conforme conceito proposto por Michel Callon (2013): ato pelo qual o indivíduo se 
insere em uma rede de relações entre humanos e não-humanos, e que produz as trocas econômico-políticas na clássica forma simplificada que o modelo do homo economicus tenderia a pressupor como o mercado. Em poucas palavras, nosso olhar está aqui na mobilização de conhecimentos cotidianos que os senegaleses acompanhados mobilizam para agenciar, paralelamente, um conjunto bem específico de atores e, assim, realizar experimentações econômicas (PINCH, 2010). De um lado, as materialidades urbanas que envolvem seu ofício, entendidas como objetos da ação humana, mas cuja eficácia social não está presa aos esforços simbólicos da mesma (M'CHAREK, 2010); de outro, os fiscais do comércio de rua que circulam pelos mesmos espaços e procuram agenciálos da perspectiva de quem procura o perigo para puni-lo.

Nesse sentido, aprender algo não é absorver um conjunto de informações prontas e as repetir para os mesmos usos originais, ou seja, não se trata de puro método. Ao invés disso, é seguir o caminho da ação indicado pela técnica, o qual, ao mesmo tempo, é capaz de transformá-la no processo do aprender fazendo. É o que nos demonstra uma das primeiras experiências de campo junto aos senegaleses de Santa Maria, em que De Césaro notou Maodo, o primeiro dos seis interlocutores a chegar à cidade, instruindo Ahmadou na venda de rua dias após sua chegada ao Brasil. A cena incomum, em que os dois senegaleses atendiam pelo mesmo ponto de venda, não se dava apenas por conta das dificuldades do recém-chegado com a língua portuguesa: Maodo tinha maior conhecimento das manhas necessárias àquele local, referentes a como vigiá-lo, a como utilizá-lo para a exposição de produtos e a como dele evadir. Ao entrar em contato com a ajuda de Maodo, Ahmadou teria de desenvolver suas próprias formas de praticar as informações obtidas de acordo com as necessidades situacionais da venda de rua. Analogamente, quando posicionado entre pontos de venda próximos, De Césaro registrava recorrentes discussões em wolof e francês entre os senegaleses acompanhados, normalmente traduzidas por um dos envolvidos momentos depois. Em grande parte desses debates, dava-se a troca de opiniões sobre como alguém fugiu ou foi pego por uma apreensão passada, sobre rumores acerca de apreensões futuras ou ainda sobre quais esquinas estavam sendo as mais utilizadas por fiscais para a abordagem. Dava-se, ali, o saber estar senegalês na venda de rua santa-mariense, em que construção e prática ocorriam paralelamente.

\section{Considerações Finais}

O objeto de nossa atenção neste artigo foi analisar, de um ponto de vista sócio histórico, o que chamamos de saber estar, conforme configurado empiricamente na venda de rua senegalesa acompanhada por De Césaro em Santa Maria entre 2016 e 2017. Diferentemente dos exercícios de confrontação institucional, em que os modos de engajamento de cada lado se formalizam no embate (nas manifestações de rua, na representação midiática de um grupo imigrante ou nas declarações oficiais do poder público, por exemplo), analisamos um tipo de agência política em que tomar a vantagem de um embate com a fiscalização era saber antecipar quando esse poderia ocorrer e como seria possível evitá-lo momento a momento, em cada local de trabalho e considerando a ênfase racial e nacional das apreensões de mercadoria. Tratamos o processo de construção desses conhecimentos 
como um de aprendizado prático de habilidades corporais situacionais e relacionais, tanto em sua eficácia de vigilância quanto em sua significação da materialidade urbana constituinte dos pontos de venda ocupados. Calçadas, esquinas, travessas, quadras, ruas e produtos estavam dentre os elementos materiais que, ali, articulavam tanto noções consensuais de espaço comum quanto diferenças de interpretação política do ofício em questão, por vezes socialmente restituídas nas interações entre os senegaleses e outros vendedores de rua.

Narramos também o caminho metodológico percorrido até a identificação e interpretação desta dimensão do trabalho de campo, a qual, até certo momento, parecia irrelevante de tão entranhada por conta das posições de classe, raça e nacionalidade do autor responsável pela investigação. Referimo-nos ao corpo e às suas formas discretas de fazer política, algo que, no trabalho etnográfico realizado, gerou uma tensão intersubjetiva específica: chegamos a notar a relevância antropológica de práticas corporais sobre e na materialidade urbana apenas por conta de experiências de embaraço vividas em campo por De Césaro, justamente por conta de como estava a pensar sua condição social e a posicionar seu corpo sobre os materiais que constituíam os pontos de venda acompanhados. Analisamos, então, os processos interacionais e sensórios por meio dos quais os vendedores de rua senegaleses (re)construíam seu próprio saber estar, que lhes permitia possibilitar o ofício irregular da venda de rua. Respeitar os trechos de calçada reservados ao fluxo de transeuntes, reconhecer quais pontos de acesso eram mais perigosos em dada conjuntura e escolher os produtos adequados ao que se esperava encontrar sensorialmente em dado ponto de venda (e sua materialidade cambiante) se configuram, então, como manhas da cidade. Em outras palavras, "formas engenhosas por meio das quais o fraco faz uso do forte", e que "dão então uma dimensão política às práticas cotidianas" (DE CERTEAU, 1984, p. 17, tradução nossa).

Tendo em vista as proposições analíticas feitas, podemos frisar a distância entre a política pública de Santa Maria para o comércio de rua e a realidade social dos vendedores de rua no que toca às potencialidades e modos de fazer pelos mesmos desenvolvidas. Mais do que grupos vulneráveis na situação de informalidade, procuramos demonstrar que se tratava de sujeitos políticos capazes de jogar à sua maneira o jogo estagnado e improdutivo das perseguições de fiscalização sancionadas em lei. À luz dessa aptidão construída na ilegalidade, procuramos expor o fracasso da política pública vigente em cumprir seu próprio fim, nomeadamente o de extinguir as possibilidades de comércio irregular nas calçadas de Santa Maria. Expressiva disto é a persistência nas operações de apreensão, enquanto respostas paliativas aos protestos discretos de lojistas do comércio formal próximo, e nada efetivas em gerar um diálogo concreto com os grupos mais impactados: os dos vendedores de rua. Assim, para uma política pública da venda de rua mais inclusiva e eficaz (considerando seus objetivos), mostra-se fundamental uma postura de compreensão e diálogo, que tome os atores cotidianos da rua como parte de uma realidade complexa e indeterminada (MASSEY, 2008), insurgente a simplificações como as que legitimam e legitimaram a repressão racista e xenófoba analisada no presente artigo. 


\section{Referências}

ALVARADO, Lina; ZUBRZYCKI, Bernarda. Redes y proyectos migratorios de los senegaleses en Argentina. In: GUIGOU, Lelio (org.). XI Actas de la Reunión de Antropología del Mercosur - Diálogos, Prácticas y visiones desde el Sur. Montevidéu: Universidad de la Republica/Facultad de Humanidades y Ciencias de la Educación, 2015. p. 1-21.

BARBOSA, Lorena Salete; DE CÉSARO, Filipe; ZANINI, Maria Catarina. Um panorama das migrações internacionais para o sul do Brasil: haitianos e senegaleses em movimento. In: ZIMERMAN, Artur (org.) Impacto dos fluxos imigratórios recentes no Brasil. Santo André: Editora da UFABC, 2017. p. 80-101.

BHABHA, Homi. O local da cultura. Belo Horizonte: Editora da Universidade Federal de Minas Gerais, 1998.

BITTENCOURT, Luís; REDIN, Giuliana. Imigrantes senegaleses no Brasil: tratamento jurídico e desafios para a garantia de direitos. In: HERÉDIA, Vânia (org.). Migrações Internacionais: o caso dos senegaleses no sul do Brasil. Caxias do Sul: Belas Letras, 2015. p. 201-218.

BOURDIEU, Pierre. The Logic of Practice. Stanford: Stanford University Press, 1990.

CALLON, Michel. Sociologie des agencements marchands: textes choisis. Paris: Presses des Mines, 2013.

CSORDAS, Thomas. Corpo/Significado/Cura. Porto Alegre: Ed. da UFRGS, 2008.

DAS, Veena. Life and Worlds: Violence and the Descent into the Ordinary. Los Angeles: University of California Press, 2007.

DE CERTEAU, Michel. The Practice of Everyday Life. Los Angeles: University of California Press, 1984.

DE CÉSARO, Filipe; ZANINI, Maria Catarina. “Tem que estar bonito pra vender": a produção senegalesa de espaços de venda em Santa Maria (Rio Grande do Sul, Brasil). Brasília: UnB, REMHU, [s.l.], v. 26, n. 52, p. 95-110, 2018.

DE CÉSARO, Filipe. “Tem que conversar, senão não vende, né?": a inserção de imigrantes senegaleses no comércio de rua de Santa Maria (RS). 2018. 245 p. Dissertação (Mestrado em Ciências Sociais) - Universidade Federal de Santa Maria, Santa Maria, 2018.

DE CÉSARO, Filipe; ZANINI, Maria Catarina. Migração senegalesa e mouridismo: um breve exercício interpretativo. In: TEDESCO, João Carlos; KLEIDERMACHER, Gisele. A imigração senegalesa no Brasil e na Argentina: múltiplos olhares. Porto Alegre: EST Edições, 2017. p. 255-274.

DE MELLO, Pedro; TEDESCO, João. Senegaleses no centro-norte do Rio Grande do Sul: imigração laboral e dinâmica social. Porto Alegre: Letra \& Vida, 2015.

DELGADO, Manuel; MALET, Daniel. El espacio público como ideología. Anales de las Jornadas Marx Siglo XXI, Rioja, v. 1, n. 1, p. 1-12, 2007.

DOS SANTOS, Daiane. Práticas e táticas de um “fazer econômico": os Kaingang do setor Pedra Lisa - TI Guarita. 2011. 122 p. Dissertação (Mestrado em Ciências Sociais) Universidade Federal de Santa Maria, Santa Maria, 2011.

ECKERT, Cornelia; ROCHA, Ana. Etnografia de rua: estudo de antropologia urbana. Iluminuras, Porto Alegre, v. 4, n. 7, p. 1-22, 2003.

FALL, Papa. Des francenabe aux modou-modou: l'émigration sénégalaise contemporaine. Dakar: L'Harmattan Sénégal, 2017.

FANON, Frantz. Pele negra, máscaras brancas. Salvador: Editora da Universidade Federal da Bahia, 2008. 
FARMER, Paul. An Anthropology of Structural Violence. Current Anthropology, Chicago, v. 45, n. 3, p. 305-325, 2004.

FONSECA, Claudia; SCALCO, Lucia; DE CASTRO, Helena. Etnografia de uma política pública: controle social pela mobilização popular. Horizontes Antropológicos, Porto Alegre, v. 24, n. 50, p. 271-303, 2018.

FOURON, George; GLICK-SCHILLER, Nina. Laços de sangue: os fundamentos raciais do Estado-nação transnacional. Revista Crítica de Ciências Sociais, Coimbra, v. 1, n. 48, p. 33-66, 1997.

GEERTZ, Clifford. A interpretação das culturas. Rio de Janeiro: LTC, 1989.

GLICK-SCHILLER, Nina; LEVITT, Peggy. Conceptualizing Simultaneity: A Transnational Social Field Perspective on Society. IMR, Nova Iorque, v. 1, n. 3, p. 1.002-1.039, 2004.

GLOVER, John. Sufism and jihad in modern Senegal: the murid order. New York: University of Rochester Press, 2007.

GUILHERME, Ana. Imigrantes haitianos e senegaleses no Brasil: trajetórias e estratégias de trabalho na cidade de Porto Alegre - RS. 2017. 110 p. Dissertação (Mestrado em Sociologia) - Universidade Federal do Rio Grande do Sul, Porto Alegre, 2017.

HARAWAY, Donna. Situated Knowledges: the Science Question in Feminism and the Privilege of Partial Perspective. Feminist Studies, Maryland, v. 14, n. 3, p. 575-599, 1988.

HEIL, Tillman. Uma infraestrutura muçulmana de chegada no Rio de Janeiro. REMHU, Brasília, v. 26, n. 52, p. $111-130,2018$.

HERÉDIA, Vânia (org.). Migrações Internacionais: o caso dos senegaleses no sul do Brasil. Caxias do Sul: Belas-Letras, 2015.

HOLANDA, Sérgio Buarque de. Raízes do Brasil. São Paulo: Companhia das Letras, 2004.HONNETH, Axel. Invisibilidad: sobre la epistemologia moral del reconocimiento. In: HONNETH, Axel. La sociedad del desprecio. Madrid: Editorial Trotta, 2011. p. 165-181.

HOOKS, Bell. Black Looks: Race and Representation. Boston: South End Press, 1992.

IBGE - INSTITUTO BRASILEIRO DE GEOGRAFIA E ESTATÍSTICA. Censo Demográfico 2010. Rio de Janeiro: IBGE, 2010. Disponível em: https://censo2010.ibge.gov.br/. Acesso em: 13 set. 2020.

JARDIM, Denise. Os Direitos Humanos dos Imigrantes: Reconfigurações normativas dos debates sobre imigrações no Brasil contemporâneo. Densidades, Buenos Aires, v. 1, n. 14, p. 67-85, 2013.

KLEIDERMACHER, Gisele. Compartiendo y disputando veredas en "Avellaneda": El caso del colectivo senegalés y la (de)construcción de relaciones interculturales en el espacio público. In: FISCHMAN, Fernando (ed.). Migraciones, movilidades e interculturalidad: nuevos espacios de (des)encuentro en la Ciudad de Buenos Aires. Buenos Aires: Teseo, 2019. p. 85-126.

KLEIDERMACHER, Gisele. Entre Cofradías y Venta Ambulante: una caracterización de la inmigración senegalesa en Buenos Aires. Cuadernos de Antropología Social, Buenos Aires, v. 1, n. 38, p. 109-130, 2013.

LATOUR, Bruno. We Have Never Been Modern. Cambridge: Harvard University Press, 1993. LE BRETON, David. A sociologia do corpo. Rio de Janeiro: Editora Vozes, 2007.

M'CHAREK, Amade. Fragile differences, relational effects: stories about the materiality of race and sex. European Journal of Women's Studies, Londres, SAGE Publications, v. 17, n. 4, p. 1-16, 2010. 
MAFFIA, Marta. Una contribución al estudio de la nueva inmigración africana subsaariana en la Argentina. Cuadernos de Antropología Social, Buenos Aires: Universidade de Buenos Aires, v. 1, n. 31, p. 7-32, 2010.

MARQUES, Juliana; CAVEDON, Neusa; SOILO, Andressa. Representações sociais e comércio popular: o caso do Shopping do Porto, Porto Alegre (RS). Revista Confluências Culturais, Joinville, Univille, v. 2, n. 1, p. 48-58, 2013.

MASSEY, Doreen. Pelo espaço: uma nova política da espacialidade. Rio de Janeiro: Bertrand Brasil, 2008.

MAUSS, Marcel. As técnicas do corpo. In: GURVITCH, Georges; LÉVY-BRUHL, Henri (org.). Sociologia e Antropologia. São Paulo: EPU, 2014. p. 401-423.

MEYER, Birgit. "There is a spirit in that image": mass-produced Jesus pictures and Protestant-Pentecostal Animation in Ghana. Comparative Studies in Society and History, Cambridge, Cambridge University Press, v. 52, n. 1, p. 100-130, 2010.

MOCELLIN, Maria. Deslocamentos e trabalho ambulante entre jovens senegaleses no Rio Grande do Sul. In: TEDESCO, João; KLEIDERMACHER, Gisele (org.). A imigração senegalesa no Brasil e na Argentina: múltiplos olhares. Porto Alegre: EST Edições, 2017. p. 339-358.

NDIAYE, Gana. Mobility and Cultural Citizenship: The Making of a Senegalese Diaspora in Multiethnic Brazil. In: MEERZON, Yana; DEAN, David; MCNEIL, Daniel (ed.). Migration and Stereotypes in Performance and Culture. Londres: Palgrave, 2019. p. 157-177.

OLIVEN, Ruben. A parte e o todo: a diversidade cultural no Brasil-Nação. Petrópolis: Vozes, 1992.

PACECCA, María Inés; CANELO, Brenda; BELCIC, Sofía. Culpar a los Barrio, y a los pobres. Los "manteros" senegaleses ante los allanamientos en el de Once. In: PITA, María Victoria; PACECCA, María Inés (ed.). Territorios de control policial: gestión de ilegalismos en la Ciudad de Buenos Aires. Buenos Aires: Facultad de Filosofía y Letras de la Universidad de Buenos, 2017. p. 199-219.

PEIRANO, Mariza. Etnografia não é método. Horizontes Antropológicos, [s.l.], v. 20, n. 42, p. 377-391, 2014.

PINCH, Trevor. Performativity and economic demonstrations: pitching quality and quantity. In: AKRICH, Madeleine et al. (dir.). Débordements: Mélanges offerts à Michel Callon. Paris: Presses des Mines, 2010. p. 369-380.

PINTO, Mateus. As metamorfoses do trabalho urbano: o caso dos comerciantes informais de Santa Maria - RS (1980-2011). 2015. 104 p. Dissertação (Mestrado em Ciências Sociais) Universidade Federal de Santa Maria, Santa Maria, 2015.

PISSOLATO, Elizabeth. Marshall Sahlins. In: ROCHA, Everardo; FRID, Marina (org.). Os antropólogos: de Edward Tylor a Pierre Clastres. Petrópolis: Vozes, 2015. p. 265-281.

POLICASTRO, Betsabe; RIVERO, Emilse. Las relaciones de intercambio en el mundo de la venta ambulante. In: $7^{\circ}$ CONGRESO NACIONAL DE ESTUDIOS DEL TRABAJO, Buenos Aires, 2005. Anais [...]. Buenos Aires, 2005.

RABOSSI, Fernando. Negociações, associações e monopólios: a política da rua em Ciudad del Este (Paraguai). Etnográfica, Lisboa, v. 15, n. 1, p. 83-107, 2011.

REITER, Paula. Contextos de origen: colonización y religiosidad en la región de Senegambia. In: TEDESCO, João; KLEIDERMACHER, Gisele (org.). A imigração senegalesa no Brasil e na Argentina: múltiplos olhares. Porto Alegre: EST Edições, 2017. p. 79-100. 
RICCIO, Bruno. Talkin' about migration - some ethnographic notes on the ambivalente representation of migrants in contemporary Senegal. Stichproben, Viena, v. 1, n. 8, p. 99-118, 2005.

SAHLINS, Marshall. Ilhas de História. Rio de Janeiro: Zahar, 2003.

SANTOS, Boaventura de Sousa. O direito e a comunidade. Revista Crítica de Ciências Sociais, Coimbra, v. 1, n. 10, p. 9-40, 1982.

SAYAD, Abdelmalek. A imigração ou os Paradoxos da Alteridade. São Paulo: EDUSP, 1998.

SCHWARCZ, Lilia Moritz. Nem preto nem branco, muito pelo contrário: cor e raça na sociabilidade brasileira. São Paulo: Claro Enigma, 2012.

SEYFERTH, Giralda. Construindo a nação: hierarquias raciais e o papel do racismo na política de imigração e colonização. In: SANTOS, Ricardo Ventura (org.). Raça, ciência e sociedade. Rio de Janeiro: Fiocruz, 1996. p. 41-58.

SOILO, Andressa. Produções Legais da Pirataria: O Streaming e a Incorporação das Demandas e Discursos Piratas no Mercado do Entretenimento Digital. Campos, Curitiba, v. 18, n. 1, p. 1-2, 2017.

STOLLER, Paul. Money has no smell: the africanization of New York City. Chicago: The University of Chicago Press, 2002.

UEBEL, Roberto. Senegaleses no Rio Grande do Sul: panorama e perfil do novo fluxo migratório "África-Sul do Brasil". In: TEDESCO, João; KLEIDERMACHER, Gisele (org.).

A imigração senegalesa no Brasil e na Argentina: múltiplos olhares. Porto Alegre: EST Edições, 2017. p. 185-208.

VEDANA, Viviane. Técnicas corporais e ritmos de trabalho nos mercados de rua: um ensaio sobre a relação entre gestos e atos de fala. In: ZANINI, Maria; SANTOS, Miriam (org.). Feiras, feirinhas e feirões: a "economia" dos centavos em foco. São Leopoldo: Oikos, 2017. p. 40-58.

VERTOVEC, Steven. Transnationalism. London: Routledge, 2009.

ZUBRZYCKI, Bernarda. Senegaleses en Argentina: un análisis de la Mouridyya y sus asociaciones religiosas. Boletín Antropológico, Bogotá, v. 29, n. 81, p. 49-64, 2011. 


\section{Filipe Seefeldt De Césaro}

Doutorando em Antropologia Social (PPGAS) pela Universidade Federal do Rio Grande do Sul (UFRGS), Mestre em Ciências Sociais (PPGCS) e Bacharel em Relações Internacionais pela Universidade Federal de Santa Maria (UFSM). Atualmente integra o Grupo de Antropologia da Economia e da Política (GAEP, PPGAS/UFRGS) e o Núcleo de Antropologia Visual (NAVISUAL, PPGAS/UFRGS). Desenvolve pesquisa na interseção entre os estudos migratórios, a antropologia urbano-visual e a antropologia econômica, com enfoque atual sobre a imigração senegalesa no Brasil.

Endereço profissional: Rua Ildo Meneghetti, n. 20, Bairro Emílio Zuñeda, Alegrete, RS. CEP: 97544-200.

E-mail: fsdecesaro@gmail.com

ORCID: https://orcid.org/0000-0002-9605-1632

\section{Maria Catarina Chitolina Zanini}

Graduada em Ciências Sociais pela Universidade Federal do Rio Grande do Sul (1987); mestre em Antropologia pela Universidade de Brasília (1997); doutora em Ciência Social (Antropologia Social) pela Universidade de São Paulo (2002); e pós-doutora pelo Museu Nacional (MN-UFRJ) (2008). Atualmente é Professora Titular da Universidade Federal de Santa Maria (UFSM), vinculada aos Programas de PósGraduação em Ciências Sociais e Programa de Pós-Graduação em História. Coordenadora do NECON/ UFSM (Núcleo de Estudos Contemporâneos). Membro do Comitê de Iniciação Científica e de Inovação Tecnológica da UFSM. Tem experiência na área de Antropologia, trabalhando principalmente com as seguintes temáticas: migrações, teoria antropológica, campesinato e etnicidade. Foi Visiting Schoolar na Universitá Ca’Foscari Venezia (Itália) em 2019. É pesquisadora Associada do NIEM-UFRJ (Núcleo de Estudos Migratórios) e ao Instituto Histórico de São Leopoldo (ISHL). É membro do Migraidh-UFSM e da Cátedra Sérgio Vieira de Mello UFSM, na qual desenvolve atividades de pesquisa, ensino e extensão sobre migração e refúgio. É mãe de dois filhos e Pesquisadora PQ 2/CNPq desde 2012.

Endereço profissional: UFSM, Av. Roraima, n. 1.000, prédio 74, sala 2.236, Santa Maria, RS.

CEP: $97105-900$.

E-mail: zanini.ufsm@gmail.com

ORCID: https://orcid.org/0000-0003-4523-9915

\section{Como referenciar este artigo:}

CÉSARO, Filipe Seefeldt de; ZANINI, Maria Catarina Chitolina. Corpo e Cidade no Comércio Senegalês em Santa Maria (RS). Ilha - Revista de Antropologia, Florianópolis, v. 23, n. 3, p. 108-129, setembro de 2021. 